\title{
Potassium: From Physiology to Clinical Implications
}

\author{
Miriam Zacchia $^{a}$ Maria Luisa Abategiovanni ${ }^{a}$ Spiros Stratigis ${ }^{b}$ \\ Giovambattista Capasso ${ }^{a}$ \\ a Section of Nephrology, Department of Cardiothoracic and Respiratory Sciences, Second University of Naples,

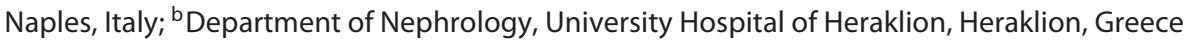

\section{Key Words}

Hypokalemia $\cdot$ Hyperkalemia $\cdot \mathrm{K}^{+}$channels $\cdot$ Aldosterone

\begin{abstract}
Background: Potassium $\left(\mathrm{K}^{+}\right)$is the major intracellular cation, with $98 \%$ of the total pool being located in the cells at a concentration of $140-150 \mathrm{mmol} / \mathrm{l}$, and only $2 \%$ in the extracellular fluid, where it ranges between 3.5 and $5 \mathrm{mmol} / \mathrm{l}$. A fine regulation of the intracellular-extracellular gradient is crucial for life, as it is the main determinant of membrane voltage; in fact, acute changes of $\mathrm{K}^{+}$plasma levels may have fatal consequences. Summary: An integrated system including an 'internal' and 'external' control prevents significant fluctuations of plasma levels in conditions of $\mathrm{K}^{+}$loading and depletion. The internal control regulates the intra-extracellular shift, a temporary mechanism able to maintain a constant $\mathrm{K}^{+}$ plasma concentration without changing the total amount of body $\mathrm{K}^{+}$. The external control is responsible for the excretion of the ingested $\mathrm{K}^{+}$, and it has the kidney as the major player. The kidney excretes nearly $90 \%$ of the daily intake. Along the proximal tubule and the thick ascending limb on Henle's loop, the amount of $\mathrm{K}^{+}$reabsorption is quite fixed (about 80 $90 \%)$; conversely, the distal nephron has the ability to adjust $\mathrm{K}^{+}$excretion in accordance with homeostatic needs. The present review analyzes: (1) the main molecular mechanisms
\end{abstract}

mediating $\mathrm{K}^{+}$reabsorption and secretion along the nephron; (2) the pathophysiology of the principal $\mathrm{K}^{+}$derangements due to renal dysfunction, and (3) the effect of ingested $\mathrm{K}^{+}$on blood pressure and renal electrolyte handling. Key Messages: Maintaining plasma $\mathrm{K}^{+}$levels in a tight range is crucial for life; thus, multiple factors are implicated in $\mathrm{K}^{+}$homeostasis, including kidney function. Recent studies have suggested that $\mathrm{K}^{+}$plasma levels, in turn, affect renal salt absorption in animal models; this effect may underlie the reduction of blood pressure observed in hypertensive subjects under $\mathrm{K}^{+}$ supplementation.

(c) 2016 S. Karger AG, Basel

\section{Potassium Homeostasis}

Potassium $\left(\mathrm{K}^{+}\right)$is the most abundant intracellular cation. Of the 3,500 $\mathrm{mEq}$ that constitute the total pool of the body, about $98 \%$ is confined to the intracellular fluid (ICF), at concentrations of $140-150 \mathrm{mEq} / \mathrm{l}$, and only $2 \%$

This study was presented at the 1st Conference of the International Network of Diagnosis and Management of Acid-Base, Electrolyte, and Fluid Alterations 'Diagnosis and Management of Acid-Base, Electrolyte and Fluid Alterations in Critically III Patients' held in Shanghai and Hangzhou on January 14-16, 2016.

\section{KARGER}

E-Mail karger@karger.com

www.karger.com/kdd
(C) 2016 S. Karger AG, Basel

2296-9381/16/0022-0072\$39.50/0
Miriam Zacchia

Section of Nephrology, Department of Cardiothoracic and Respiratory Sciences Second University of Naples

Via Pansini 5, IT-80131 Naples (Italy)

E-Mail miriamzacchia@ virgilio.it 


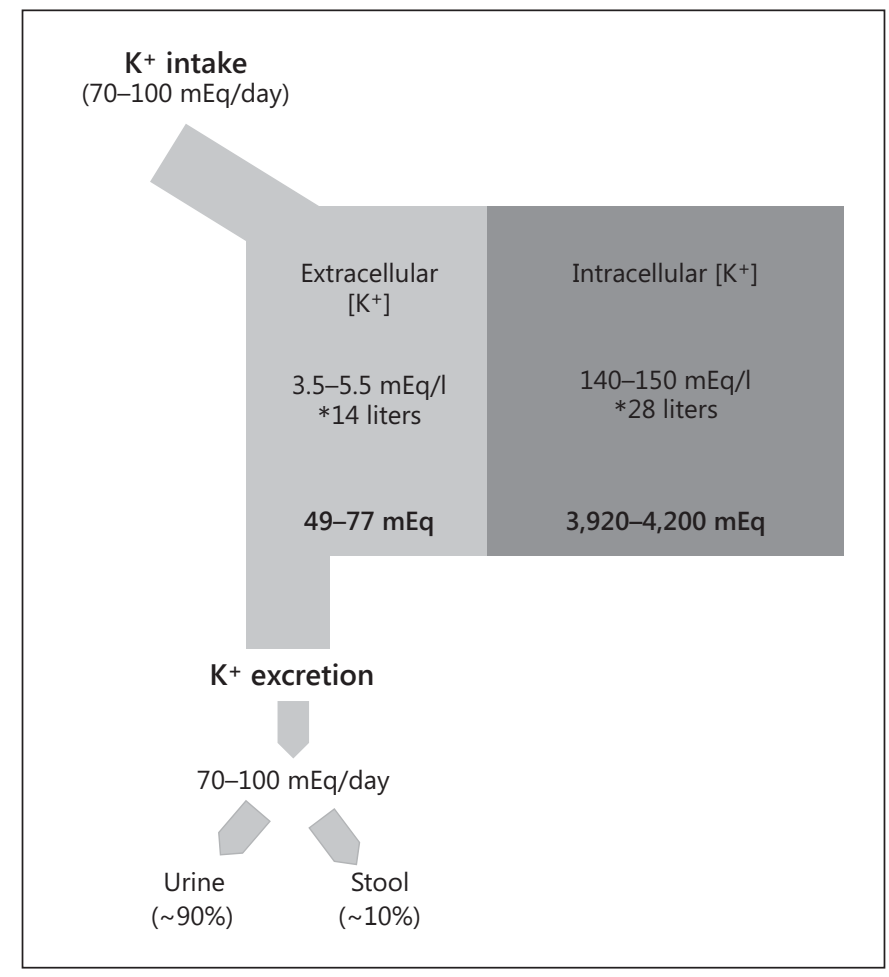

Fig. 1. Schematic representation of $\mathrm{K}^{+}$homeostasis.

(nearly $70 \mathrm{mEq}$ ) is located in the extracellular fluids (ECF), where it ranges from 3.5 to $5 \mathrm{mEq} / \mathrm{l}$. The $\mathrm{K}^{+}$gradient between the ICF and the ECF is based on the activity of the $\mathrm{Na}-\mathrm{K}$ ATPase, located on the plasma membrane of all animal cells. As the intracellular $\mathrm{K}^{+}$pool is much higher than the extracellular pool, clearly changes of total $\mathrm{K}^{+}$content and/or distribution cause more dramatic fluctuations of extracellular rather than intracellular $\mathrm{K}^{+}$concentration $\left[\mathrm{K}^{+}\right]$. However, several factors modulate $\mathrm{K}^{+}$redistribution between the ICF and the ECF and its excretion in order to maintain the extracellular concentration in a tight range.

It is well known that an ingested $\mathrm{K}^{+}$load does not result in a significant increase in plasma $\left[\mathrm{K}^{+}\right]$. Theoretically, an intake of $35 \mathrm{mEq}$ of $\mathrm{K}^{+}$would raise its plasma level by $2.5 \mathrm{mEq} / \mathrm{l}$ in humans if the distribution was totally extracellular. In contrast, only about a quarter of the ingested $\mathrm{K}^{+}$remains in the ECF, as a large cellular storage reservoir (including muscle, liver and red blood cells) buffers plasma $\mathrm{K}^{+}$upon its intake.

Both internal and external homeostasis contributes to maintaining a normal $\mathrm{K}^{+}$balance, by controlling its distribution (the first) and its excretion (the second) in either conditions of $\mathrm{K}^{+}$loading and $\mathrm{K}^{+}$depletion (fig. 1).
The internal $\mathrm{K}^{+}$homeostasis is mainly dependent on hormones such as insulin and catecholamines; in addition, acid base balance and plasma osmolality regulate cellular $\mathrm{K}^{+}$uptake. This process is extremely efficient and guarantees constant plasma $\left[\mathrm{K}^{+}\right]$through the regulation of the $\mathrm{Na}^{+}-\mathrm{K}^{+}$ATPase activity. The kidney is the main determinant of external $\mathrm{K}^{+}$homeostasis, being responsible for the excretion of $90 \%$ of the $\mathrm{K}^{+}$ingested, versus $10 \%$ eliminated via stools.

\section{Renal Homeostasis of $\mathrm{K}^{+}$}

A small fraction of plasmatic $\mathrm{K}^{+}$ions may bind nonfilterable proteins, with a consequent restriction to glomerular filtration. Unbound $\mathrm{K}^{+}$is freely filtered across the glomerulus, and the concentration of $\mathrm{K}$ in the glomerular filtrate is equal to the plasmatic concentration.

Clearance studies during the 1940s and the 1950s demonstrated that the bulk of tubular $\mathrm{K}^{+}$reabsorption occurs along the proximal tubule (PT) and the thick ascending limb on Henle's loop (TAL) [1] (fig. 2). In vivo micropuncture experiments in the 1960 s showed that $~ 50 \%$ of the filtered load reaches the late PCT in the collections from tubular fluids [2], indicating that the PT reabsorbs the majority of the filtered load. The evidence of a strong association between the rate of fluid and $\mathrm{K}^{+}$reabsorption suggests that, at least in part, $\mathrm{K}^{+}$absorption occurs with a solvent drag mechanism. In addition, a paracellular diffusion from the lumen to the interstitium is driven by the difference of concentration (that is higher in the lumen upon fluid absorption) and by the favorable electrochemical gradient, especially along the latest part of the PT. The role of transcellular transport is partially known. The basolateral $\mathrm{Na}-\mathrm{K}$ ATPase mediates the electrogenic transport of $\mathrm{K}^{+}$from the interstitium to the cell, generating a high intracellular $\left[\mathrm{K}^{+}\right]$and a cell-positive electric potential. Along the final part of the PT (segment S3), which includes the fraction of the PT that enters the outer medulla, $\mathrm{K}^{+}$is secreted into the luminal fluid. The presence of $\mathrm{K}^{+}$channels has been demonstrated at both the basolateral and luminal sites. The $\mathrm{K}^{+}$efflux to the lumen and to the interstitium generates a cell-negative gradient that provides the driving force for cation reabsorption. Immunofluorescence studies have demonstrated the presence of KCNE1 and KCNQ1 proteins on the brush-border membrane of PT, which colocalize to form an apical $\mathrm{K}^{+}$channel. $\mathrm{KCNE}^{-/-}$mice show hypokalemia and volume depletion [3]. Micropuncture studies showed a strong reduction of $\mathrm{K}^{+}$secretion along the PT. These channels are supposed to mediate membrane repolarization, as $\mathrm{Na}^{+}$substrate absorption leads to membrane de- 
Fig. 2. $\mathrm{K}^{+}$reabsorption and secretion along $\mathrm{K}^{+}$handling along the nephron the nephron.

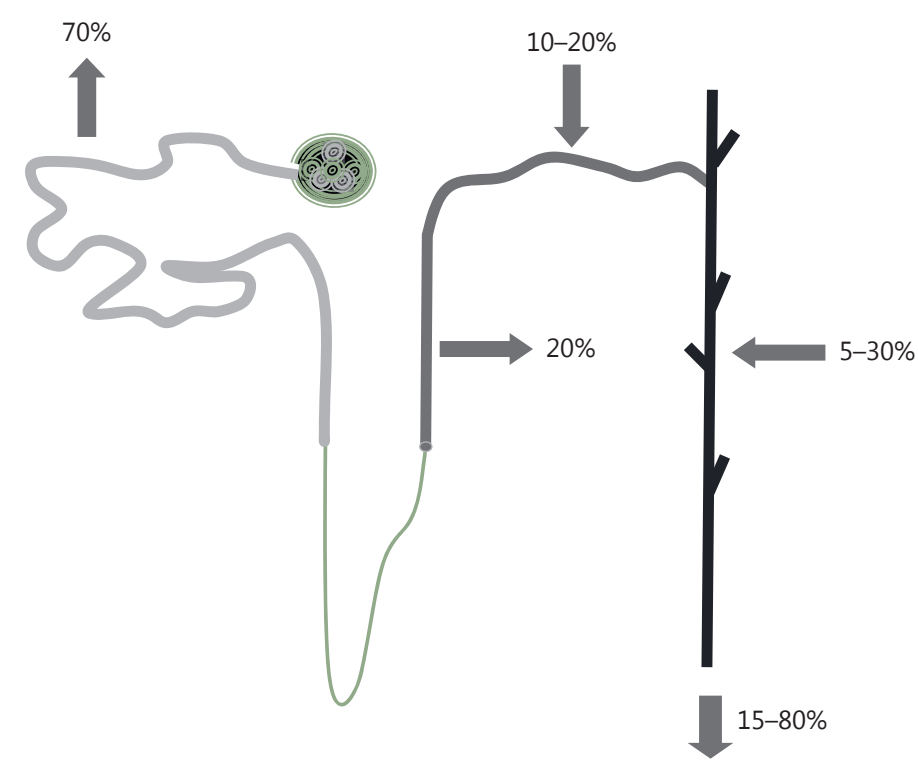

polarization. Accordingly, a defective function of the KCNE-KCNQ1 channels, as in $\mathrm{KCNE}^{-/-}$mice, affects solute absorption leading to osmotic polyuria. Luminal $\left[\mathrm{K}^{+}\right]$concentration at the tip of the Henle's loop is 10 -fold the plasma concentration.

Along the descending limb, $\mathrm{K}^{+}$is delivered to the tubular fluid. It has been postulated that $\mathrm{K}^{+}$ions are trapped in the medulla by the countercurrent mechanism after being actively absorbed along the TAL and passively enter the lumen along the descending limb. $\mathrm{K}^{+}$reabsorption along the TAL is primary mediated by the Na-K-2Cl cotransporter (NKCC2), following the $\mathrm{Na}^{+}$-favorable gradient generated by the Na-K ATPase. The high intracellular $\left[\mathrm{K}^{+}\right]$favors its recycling back to the lumen through the apical $\mathrm{K}^{+}$channels ROMK. Several lines of evidence demonstrate that $\mathrm{K}^{+}$recycling through $\mathrm{ROMK}$ is crucial to guarantee $\mathrm{Na}-\mathrm{K}-2 \mathrm{Cl}$ reabsorption; the uptake of these ions is dramatically reduced by either reducing luminal $\left[\mathrm{K}^{+}\right]$and by blocking ROMK activity [4]. At the basolateral level, the $\mathrm{K}^{+}$efflux is mediated by the $\mathrm{K}-\mathrm{Cl}$ and $\mathrm{K}$ $\mathrm{HCO}_{3}{ }^{-}$cotransporters besides the $\mathrm{K}$ channels.

Only $10 \%$ of the filtered load reaches the distal nephron. The evidence that the amount of $\mathrm{K}^{+}$excreted could exceed the amount of $\mathrm{K}^{+}$filtered suggested the presence of $\mathrm{K}^{+}$secretion along the nephron. The final $\mathrm{K}^{+}$excretion (which is generally $10-20 \%$ of the filtered load) is mainly a function of distal secretion. The distal convolute tubule
(DCT) has a minor role in $\mathrm{K}^{+}$secretion compared with the connecting tubule (CNT) and the cortical collecting duct (CCD). Microperfusion studies in rats showed that the DCTs are able to secrete $\mathrm{K}^{+}$through the $\mathrm{K}-\mathrm{Cl}$ cotransporter [5].

At the basolateral level, the presence of the $\mathrm{K}^{+}$channel KCNJ 10 kir4.1 has been shown to mediate $\mathrm{K}^{+}$recycling to the interstitium, safeguarding the activity of the $\mathrm{Na}-\mathrm{K}$ ATPase pump; genetic defects of this channel lead to salt wasting because of a reduced activity of the $\mathrm{Na}-\mathrm{K}$ ATPase.

The CNT and collecting duct (CD) are the main segments mediating $\mathrm{K}^{+}$secretion. Along these segments, the epithelium is constituted mainly of principal cells, which represent $70-75 \%$ of the total population; these cells mainly mediate $\mathrm{Na}$ reabsorption and $\mathrm{K}^{+}$secretion. The latter requires several transmembrane proteins: first, the basolateral Na-K ATPase increasing the intracellular $\left[\mathrm{K}^{+}\right]$ provides the gradient for $\mathrm{K}^{+}$efflux; in addition, apical $\mathrm{Na}^{+}$ entry through the $\mathrm{ENaC}$ channels provides a favorable electrochemical gradient for $\mathrm{K}^{+}$secretion; eventually, $\mathrm{K}^{+}$ exit to the lumen is mediated by the ROMK channels, BK (big potassium) channels and $\mathrm{K}-\mathrm{Cl}$ cotransporter. Several lines of evidence demonstrate that BK channels mediate the bulk of $\mathrm{K}^{+}$secretion along the $\mathrm{CNT}$ and $\mathrm{CCD}$ in response to a high urinary flux [6]. Those channels are relatively inactive under normal conditions but are activated by a high urinary flow. 
A small fraction of epithelial cells along the distal nephron is represented by intercalated cells that are scattered among the principal cells. These cells are able to reabsorb $\mathrm{K}^{+}$under certain conditions, such as $\mathrm{K}^{+}$depletion. The $\alpha$-intercalated cells show several isoforms of $\mathrm{K}-\mathrm{H}$ ATPase. The latter is also expressed along the gastric and colonic mucosa, and it is inhibited by omeprazole. These transporters are activated by hypokalemia and may serve as a compensatory machinery mediating increased $\mathrm{K}^{+}$reabsorption when needed.

As the rate of $\mathrm{K}^{+}$reabsorption along the PT and the TAL is mainly fixed, the final excretion depends mainly on $\mathrm{K}$ secretion along the distal nephron. This process is under a fine regulation by several factors.

\section{Feedback Control of $\mathrm{K}^{+}$Homeostasis}

The feedback control in physiology is, by definition, a regulatory mechanism of a biological function that maintains specific parameters (temperature, $\mathrm{pH}$, electrolyte levels, etc.) in the optimal range through an internal control. The negative feedback implicates the sensation of a stimulus (high plasma $\left[\mathrm{K}^{+}\right]$), which in turn activates some effectors that finally return the parameter back to normal. Several hormones constitute the effectors of the feedback control of $\mathrm{K}^{+}$homeostasis. A $\mathrm{K}^{+}$-rich meal induces the pancreatic secretion of insulin, which stimulates the Na-K pump, minimizing the increase in plasma $\left[\mathrm{K}^{+}\right]$by promoting $\mathrm{K}^{+}$uptake into the muscle cells [7]. When $\mathrm{K}^{+}$plasma levels increase enough, hyperkalemia induces aldosterone secretion. Aldosterone, in turn, promotes renal $\mathrm{K}^{+}$ secretion through the upregulation of both the basolateral Na-K ATPase and the luminal $\mathrm{K}^{+}$channels along the principal cells. In addition, aldosterone enhances $\mathrm{K}^{+}$secretion along the colon, an essential function especially in the presence of kidney disease. Conversely, when the extracellular $\mathrm{K}^{+}$content is reduced because of a deficient intake or an increased urine excretion, $\mathrm{K}^{+}$is released from the intracellular space to the plasma. In this condition, skeletal muscle becomes insulin resistant to $\mathrm{K}^{+}$(but not glucose) uptake, even before plasma $\left[\mathrm{K}^{+}\right]$decreases. In addition, hypokalemia leads to the downregulation of the skeletal muscle Na-K ATPase isoform 2, with the consequent leak of $\mathrm{K}^{+}$to the plasma, and to the inhibition of aldosterone release, with the reduction of urinary $\mathrm{K}^{+}$secretion.

\section{Feedforward Control of $\mathrm{K}^{+}$Homeostasis}

A feedforward loop refers to a control system that responds to a specific stimulus in a predefined manner. Besides the feedback control, several lines of evidence sug-

Potassium: From Physiology to Clinical Implications
Table 1. Main features of BS and GS patients

\begin{tabular}{ll}
\hline BS & GS \\
\hline $\begin{array}{l}\text { Polyhydramnios (due to fetus excessive } \\
\text { urine output) }\end{array}$ & $\begin{array}{l}\text { Hypokalemia } \\
\text { Metabolic alkalosis }\end{array}$ \\
$\begin{array}{l}\text { Polyuria and subsequent polydipsia } \\
\text { Dehydration due to volume depletion }\end{array}$ & Hypomagnesemia \\
$\begin{array}{l}\text { Hypokalemic metabolic alkalosis } \\
\text { Hypercalciuria/nephrocalcinosis }\end{array}$ & \\
\hline
\end{tabular}

gest that $\mathrm{K}^{+}$homeostasis is under a feedforward control that is inducted when minimal changes in plasma $\left[\mathrm{K}^{+}\right]$ occur. It has been established that the regulation of plasma aldosterone by $\mathrm{K}^{+}$is activated when the plasma $\left[\mathrm{K}^{+}\right]$ is higher or lower than normal, with little effect when it is within the physiological range. In animal models, it has been shown that after an oral $\mathrm{K}^{+}$load, significant urinary $\mathrm{K}^{+}$excretion occurs without changes in plasma aldosterone concentration. However, the existence of a kaliuretic reflex has been suggested arising from an unknown sensor in the splanchnic bed.

The $\mathrm{K}^{+}$adaptation refers to the increased $\mathrm{K}^{+}$secretion along the distal nephron after an ingested $\mathrm{K}^{+}$load, without any significant change in aldosterone plasma levels. In animal models, this adaptation is mediated by an increased ROMK channel, Na-K ATPase and ENaC activity.

Glucagon has been proposed as a potential effector of the feedforward control. This hormone is secreted upon a protein-rich meal, and intraportal glucagon infusion produces significant increases in renal blood flow and the glomerular filtration rate. The feedforward regulation of $\mathrm{K}^{+}$homeostasis may include several mechanisms: (1) insulin release that rapidly induces cellular $\mathrm{K}^{+}$uptake into insulin-responsive tissues; (2) glucagon secretion that promotes renal $\mathrm{K}^{+}$excretion after a protein-rich meal; (3) a yet-unidentified gut sensor that enhances renal $\mathrm{K}^{+}$excretion after ingestion. When plasma $\left[\mathrm{K}^{+}\right]$increases beyond these layers of control, feedback regulation is activated.

\section{Hypokalemia: Lessons from the Salt-Losing Tubulopathies}

Genetic studies of inborn errors resulting in renal salt wasting have provided novel insights into the pathophysiology of renal electrolyte handling. Additional studies on engineered mice and cell culture have further highlighted 
the function of specific transport proteins and the molecular pathways regulating their activity.

Bartter (BS) and Gitelman (GS) syndromes are genetic disorders leading to hypokalemic metabolic alkalosis due to renal loss, with a compensatory activation of the RAAS axis. Genetic studies have shed light onto the molecular basis underlying these disorders that have long been considered two forms of the same disease (table 1).

\section{Bartter Syndrome}

BS is a rare tubular dysfunction caused by a genetic mutation leading to a defective $\mathrm{NaCl}$ absorption along the TAL. To date, mutations of five genes have been described. The defect determines fluid and electrolyte loss resulting in hypovolemia, with a compensatory activation of the RAS axis, leading to hypokalemia and metabolic alkalosis.

\section{Genetics}

BS type I is caused by mutations of the $S L C 12 A 1$ gene, encoding the kidney-specific $\mathrm{Na}-\mathrm{K}-2 \mathrm{Cl}$ cotransporter NKCC2. BS type II depends on KCNJ1 mutations, leading to a defective function of the $\mathrm{K}^{+}$channel ROMK. Immunostaining studies have shown an apical distribution of ROMK channels along the TAL, DCT and CD in rats, consistent with a role in $\mathrm{K}^{+}$secretion along the renal epithelia. Along the TAL, ROMK channels mediate $\mathrm{K}^{+}$efflux back to the lumen, favoring $\mathrm{NaCl}$ reabsorption by supplying $\mathrm{K}^{+}$to the NKCC2, as described above. Thus, it is not surprising that the loss of function of ROMK results in a defective fluid and salt reabsorption. As a consequence of $\mathrm{NaCl}$ and fluid loss, a stimulation of $\mathrm{K}^{+}$secretion along the distal nephron leads to hypokalemia, a hallmark of all forms of BS. Interestingly, patients carrying KCNJ1 mutations may show hyperkalemia as an initial sign of the disease, soon after birth; then, this defect is even reversed [8]. Micropuncture [9] and clearance [10] studies in young rats have demonstrated limited ability in $\mathrm{K}^{+}$secretion compared with adults. Accordingly, in microperfused CCD from mammalians, $\mathrm{K}^{+}$secretion is low in newborns and cannot be stimulated by tubular flow [11]. This defective adaptation has been linked to the low expression of the apical BK channels that are known to mediate the flux-dependent $\mathrm{K}$ secretion.

BS type III depends on the mutation of the CLCKNB gene, encoding the basolateral $\mathrm{Cl}^{-}$channel, $\mathrm{CLC}-\mathrm{Kb}$. Two proteins, CLC-Kb and CLC-Ka, encoded by the CLCNKb and CLCNKa genes, respectively, mediate the basolateral $\mathrm{Cl}^{-}$efflux along this segment. Both proteins are associated with the Barttin subunit, essential for protein insertion into the plasma membrane. There is no evidence of
CLCKNA mutations in BS. ClCk1 (the ortholog of CLC$\mathrm{Ka}$ )-deficient mice show a phenotype of nephrogenic diabetes insipidus.

The fact that CLCKb is very abundant along the DT explains why this variant of BS is less commonly associated with a defect of urinary concentration and with hypercalciuria. Often, those patients show an overlapping phenotype between BS and GS.

BS type IV refers to the BS forms correlated with BSND mutations, encoding for the Barttin subunit of the basolateral chloride channel. The CLC-K/Barttin Cl channels also localize to the cochlea. In fact, patients carrying a BSND mutation show a phenotype of BS associated with hearing defects.

BS type $\mathrm{V}$ is caused by gain-of-function mutations of the calcium-sensing receptor (CaSR). The protein is expressed in the parathyroid and in the kidney, and it is mainly involved in calcium homeostasis. Along the TAL, the CaSR is expressed on the basolateral membrane. In the presence of hypercalcemia, the protein inhibits salt absorption, with consequent calcium and magnesium loss. Some case reports show that activating mutations of the CaSR show a BS phenotype.

\section{Clinical Presentation}

BS may have different clinical presentations:

- Antenatal BS, or hyper-prostaglandin E2 syndrome, refers to the most severe form, characterized by polyhydramnios due to excessive urinary output and premature birth. BS types I and II and sometimes type III are associated with this clinical subtype. After birth, patients commonly show fever, vomiting and lethargy. Biochemical analysis shows metabolic alkalosis, hypokalemia, iso-hypostenuria and hypercalciuria. Nephrocalcinosis is frequent. A high urinary excretion of prostaglandin E2 or its metabolites is typical. High renin and aldosterone plasma levels are due to volume depletion. The cause of the high urinary and plasmatic prostaglandin levels is still unknown; it is possible that this is due to the defective $\mathrm{NaCl}$ reabsorption along the TAL.

- Classic BS is sustained by BS type III. The onset of the disease occurs generally during childhood. The clinical course is milder than in the antenatal subtype; patients show polyuria and polydipsia; nephrocalcinosis is uncommon.

- BS with sensorineural deafness. BS type IV may have a high variable of the severity of hydroelectrolyte imbalance. The clinical form may range from the antenatal form to mild hydroelectrolyte defects. Hearing loss is typical for BS type IV. 


\section{Gitelman Syndrome}

Genetics

GS is a genetic tubular disorder sharing several analogies with BS. It is caused by mutations of the SLC12A3 gene, encoding the thiazide-sensitive sodium chloride cotransporter (NCC). Patients with heterozygous mutations do not show the disease; some studies have shown that they may have a tendency to exhibit hypotension, while complete GS phenotype occurs solely when the mutation is in homozygosis. A minority of patients show mutations of the CLCNKB gene, which is also responsible for BS type III. The presence of the basolateral $\mathrm{Cl}^{-}$channel along the TAL and DT explains why patients carrying CLCKNB mutations often show a phenotype overlapping between BS and GS.

Pathophysiology and Clinical Presentation

The defective $\mathrm{NaCl}$ absorption along the DCT leads to an increased $\mathrm{Na}^{+}$load to the distal nephron. The latter, together with the activation of the RAAS induced by volume depletion, stimulates $\mathrm{Na}^{+}$reabsorption along the $\mathrm{CD}$, which in turn favors $\mathrm{H}^{+}$and $\mathrm{K}^{+}$secretion.

Besides hypokalemia and metabolic alkalosis, hypomagnesemia and hypocalciuria are other hallmarks of the disease. The renal handling of $\mathrm{Ca}^{2+}$ and $\mathrm{Mg}^{2+}$ is only partially understood in GS.

Normally, $\mathrm{Mg}^{2+}$ is freely filtered by the glomerulus; it is then reabsorbed along the PT by $10 \%$ and along the TAL by $50-70 \%$ via a paracellular pathway [12]. Along the DT, $\mathrm{Mg}^{2+}$ reabsorption occurs through a transcellular pathway, via the TRPM6 channels. Mice lacking the NCC cotransporter show a downregulation of TRPM6 in either the DCT or in the intestine, leading to stool and urinary $\mathrm{Mg}^{2+}$ loss.

Similar to $\mathrm{Mg}^{2+}, \mathrm{Ca}^{2+}$ ions are filtered by the glomerulus and reabsorbed along the PT and TAL in a paracellular manner, following the favorable electrochemical gradient. Transcellular $\mathrm{Ca}^{2+}$ absorption occurs along the DCT, mediated by the voltage-sensitive $\mathrm{Ca}^{2+}$ channel TRPV5 expressed on the apical membrane.

Low urine calcium excretion in GS is attributed to two mechanisms: (1) the volume contraction induced by the defective salt absorption along the CDT leads to a compensatory increased $\mathrm{NaCl}$ absorption along the $\mathrm{PT}$, which also drives paracellular $\mathrm{Ca}^{2+}$ absorption; (2) NCC inactivation determines cell hyperpolarization, which activates TRPV 5 channels leading to the increased $\mathrm{Ca}^{2+}$ absorption [13].

\section{Hyperkalemia in the Setting of Renal Failure}

Hyperkalemia is a potential life-threatening electrolyte imbalance. This condition may result from the disruption of the equilibrium between the ICF and ECF concentrations or from an increased total body content, caused by excessive food intake or defective excretion. The resulting increased plasma $\left[\mathrm{K}^{+}\right]$leads to a partial membrane depolarization that may eventually cause cardioplegia and skeletal muscle paralysis.

In the clinical setting, chronic renal failure is the most common risk factor for chronic hyperkalemia [14]. As the GFR declines, plasma $\left[\mathrm{K}^{+}\right]$is maintained in the normal range until the latest stages of renal failure. A previous study demonstrated that stage IV CKD patients showed the same increase in $\mathrm{K}^{+}$secretion after $\mathrm{K}^{+}$ingestion compared with people with normal renal function, indicating a conserved ability to excrete $\mathrm{K}^{+}$. This is possible because the remaining nephrons enhance their ability to secrete $\mathrm{K}^{+}$through the upregulation of the entire machinery mediating its secretion along the distal nephron, including the Na-K ATPase, the ENaC and ROMK channels [15]. However, those patients showed a higher increase in plasma $\left[\mathrm{K}^{+}\right]$after $\mathrm{K}^{+}$ingestion. This evidence suggested that $\mathrm{CKD}$ patients may have an impaired internal $\mathrm{K}^{+}$homeostasis. However, this issue has been extensively investigated in animal models and humans, with conflicting results. Thus, whether the tissue $\mathrm{K}^{+}$distribution is impaired in CKD is still debated [15]. When the GFR falls below 15 $\mathrm{ml} / \mathrm{min}$, the adaptive mechanisms that enable the remaining nephrons to excrete the ingested $\mathrm{K}^{+}$are overwhelmed, and hyperkalemia may occur.

Several pathophysiological factors favor the development of hyperkalemia in CKD patients: (1) the reduced urine output in the latest stage of CKD impairs the fluxdependent $\mathrm{K}^{+}$secretion; (2) the presence of metabolic acidosis, another common complication of the late CKD, affects $\mathrm{K}^{+}$distribution between the ICF and ECF by favoring $\mathrm{K}^{+}$release to the extracellular space; (3) the presence of comorbidities, such as diabetes, with the reduction in insulin plasma levels and plasma hyperosmolality, increases the risk of hyperkalemia, and (4) the use of medications such as ACE inhibitors or ARBs.

Deregulation of the RAS axis has a proven critical role in determining hyperkalemia in CKD patients. Several studies have demonstrated that the use of ACE inhibitors and/or ARBs reduces the intraglomerular pressure, reduces tubulointerstitial damage and slows the progression of kidney disease in animal models of CKD. Accordingly, several trials have demonstrated the beneficial ef- 


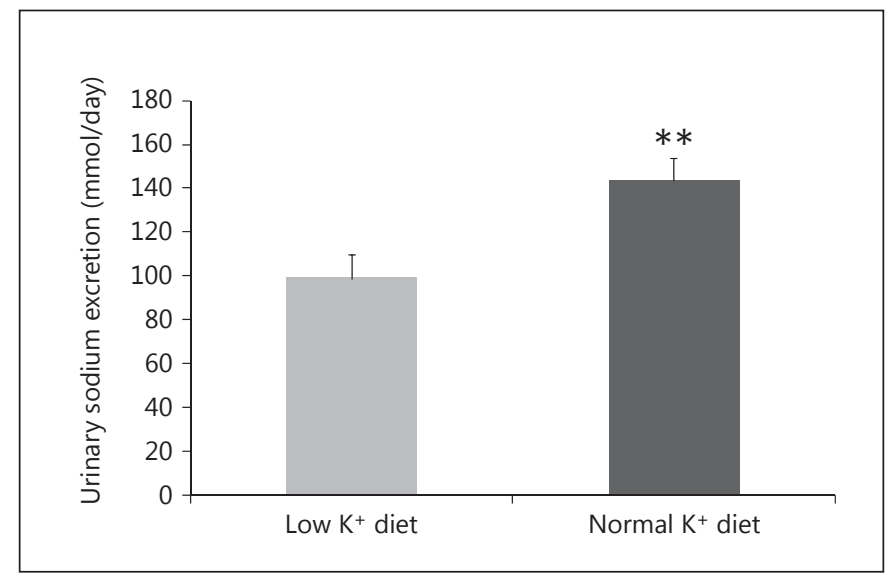

Fig. 3. Effect of $\mathrm{K}^{+}$intake on urine $\mathrm{Na}^{+}$excretion. ${ }^{* *} \mathrm{p}<0.001 \mathrm{com}-$ pared with low $\mathrm{K}^{+}$diet. Adapted from Krishna et al. [25].

fects of ACE and/or ARBs in CKD patients. The RAS inhibitor therapy has been shown to reduce the risk of renal failure and cardiovascular events in CKD patients, rendering RAS inhibitors the first-choice antihypertensive drugs [16]. However, the intensive treatment with RAS inhibitors in CKD patients increases the risk of adverse effects. The risk to develop hyperkalemia in stage 3 or higher CKD patients is low in those taking monotherapy with RAS blockers, unless volume depletion occurs [17]. Conversely, dual RAS blockade, even though it has been proven to reduce proteinuria, does not show significant benefits in slowing the progression of kidney disease or in reducing cardiovascular events, but increases the risk of hyperkalemia. The most recent KDIGO recommendations declare that there are insufficient data to prove a real benefit of dual RAS blockade in slowing CKD progression, so it should not be routinely prescribed.

\section{Effect of Plasma $\left[\mathrm{K}^{+}\right]$on Blood Pressure}

Epidemiological studies have demonstrated an inverse relationship between hypertension and dietary $\mathrm{K}^{+}$intake. In the 1980s, Lever et al. [18] demonstrated that exchangeable total $\mathrm{Na}^{+}$and $\mathrm{K}^{+}$showed a positive and negative correlation, respectively, with hypertension. Further independent survey studies have shown that low $\mathrm{K}^{+}$intake correlates with high blood pressure [19]. A recent meta-analysis has demonstrated that $\mathrm{K}^{+}$supplementation resulted in a reduction of systolic and diastolic blood pressure by 4.7 and $3.5 \mathrm{~mm} \mathrm{Hg}$, respectively, with a great- er effect in hypertensive patients [20]. Altogether, a number of epidemiological studies strongly suggest that increasing dietary $\mathrm{K}^{+}$intake has a protective effect on the development of hypertension [21]. Whether $\mathrm{K}^{+}$may have a regulatory effect on the control of blood pressure is an object of intensive investigations.

A number of potential mechanisms have been implicated, including sodium retention, hormonal activation and direct effect on the vascular smooth muscle function. $\mathrm{KCl}$ supplementation has been shown to inhibit, while low $\mathrm{KCl}$ diet enhances, $\mathrm{NaCl}$ reabsorption along the DCT, via the upregulation of NCC [22].

Dietary $\mathrm{K}^{+}$loading, as well as increased plasma $\left[\mathrm{K}^{+}\right]$by $\mathrm{KCl}$ infusion, resulted in increased urinary $\mathrm{Na}^{+}$excretion in association with reduced NCC phosphorylation in rats [23] (fig. 3). These findings suggest that $\mathrm{K}^{+}$dietary intake, through changes in plasma $\left[\mathrm{K}^{+}\right]$, modulate NCC activity, and therefore $\mathrm{NaCl}$ balance. Genetic diseases leading to the activation (Gordon syndrome) and inactivation (GS) of NCC cause opposite effects on plasma $\left[\mathrm{K}^{+}\right]$, namely hyperkalemia and hypokalemia, respectively. However, it is not surprising that extracellular $\left[\mathrm{K}^{+}\right]$may modulate NCC function.

Terker et al. [24] have recently demonstrated that extracellular $\left[\mathrm{K}^{+}\right]$regulates NCC function directly, without hormonal mediation. They showed that plasma $\left[\mathrm{K}^{+}\right]$affects urinary $\mathrm{K}^{+}$excretion by altering $\mathrm{Na}^{+}$delivery to the CNT. Low $\mathrm{K}^{+}$intake, leading to low plasma $\left[\mathrm{K}^{+}\right]$, hyperpolarizes plasma membrane and causes a reduction of intracellular $\left[\mathrm{Cl}^{-}\right]$in the DCT. The latter has been shown to activate NCC via the WNK pathway, inducing a temporary increase in blood pressure in mice. This study indicates that plasma $\left[\mathrm{K}^{+}\right]$modulates NCC function in a hormone-independent manner, through changes in intracellular $\left[\mathrm{Cl}^{-}\right]$that in turn modulate the function of WNK kinases, known regulatory proteins of several transporters, including NCC.

The opposite effect is supposed to be determined by high $\mathrm{K}^{+}$intake, which may lead to NCC inhibition with consequent increased $\mathrm{Na}$ delivery to the distal nephron, resulting in increased $\mathrm{Na}^{+}$absorption and $\mathrm{K}^{+}$secretion.

\section{Conflict of Interest Statement}

All authors declared no competing interests. 


\section{References}

1 Giebisch G, Krapf R, Wagner C: Renal and extrarenal regulation of potassium. Kidney Int 2007;72:397-410.

-2 Malnic G, Klose RM, Giebisch G: Micropuncture study of renal potassium excretion in the rat. Am J Physiol 1964;206:674-686.

$\checkmark 3$ Warth R, Barhanin J: The multifaceted phenotype of the knockout mouse for the KCNE1 potassium channel gene. Am J Physiol Regul Integr Comp Physiol 2002;282:R639-R648.

$\checkmark 4$ Wang T, Wang WH, Klein-Robbenhaar G, Giebisch G: Effects of a novel KATP channel blocker on renal tubule function and $\mathrm{K}$ channel activity. J Pharmacol Exp Ther 1995;273: 1382-1389.

$\checkmark 5$ Velázquez H, Silva T, Andújar E, Desir GV, Ellison DH, Greger R: The distal convoluted tubule of rabbit kidney does not express a functional sodium channel. Am J Physiol Renal Physiol 2001;280:F530-F539.

$\checkmark 6$ Woda CB, Miyawaki N, Ramalakshmi S, Ramkumar M, Rojas R, Zavilowitz B, Kleyman TR, Satlin LM: Ontogeny of flow-stimulated potassium secretion in rabbit cortical collecting duct: functional and molecular aspects. Am J Physiol Renal Physiol 2003, 285:F629-F639.

7 Palmer BF: Regulation of potassium homeostasis. Clin J Am Soc Nephrol 2015;10:1050 1060.

-8 Cantone A, Yang X, Yan Q, Giebisch G, Hebert SC, Wang T: Mouse model of type II Bartter's syndrome. I. Upregulation of thiazide-sensitive $\mathrm{Na}-\mathrm{Cl}$ cotransport activity. Am J Physiol Renal Physiol 2008;294:F1366F1372.
$>9$ Lelievre-Pegorier M, Merlet-Benichou C, Roinel N, de Rouffignac C: Developmental pattern of water and electrolyte transport in rat superficial nephrons. Am J Physiol 1983; 245:F15-F21.

10 Kleinman LI, Banks RO: Segmental nephron sodium and potassium reabsorption in newborn and adult dogs during saline expansion. Proc Soc Exp Biol Med 1983;173:231-237.

11 Satlin LM: Regulation of potassium transport in the maturing kidney. Semin Nephrol 1999; 19:155-165.

12 Graziani G1, Fedeli C, Moroni L, Cosmai L, Badalamenti S, Ponticelli C: Gitelman syndrome: pathophysiological and clinical aspects. QJM 2010;103:741-748.

13 Unwin RJ, Capasso G: Bartter's and Gitelman's syndromes: their relationship to the actions of loop and thiazide diuretics. Curr Opin Pharmacol 2006;6:208-213.

14 Dunn JD, Benton WW, Orozco-Torrentera E, Adamson RT: The burden of hyperkalemia in patients with cardiovascular and renal disease. Am J Manag Care 2015;21(suppl):s307s315.

15 Gennari FJ, Segal AS: Hyperkalemia: an adap tive response in chronic renal insufficiency. Kidney Int 2002;62:1-9.

16 Xie X, Liu Y, Perkovic V, Li X, Ninomiya T, Hou W, Zhao N, Liu L, Lv J, Zhang H, Wang $\mathrm{H}$ : Renin-angiotensin system inhibitors and kidney and cardiovascular outcomes in patients with CKD: A Bayesian Network metaanalysis of randomized clinical trials. Am J Kidney Dis 2016;67:728-741.

$\checkmark 17$ Lazich I, Bakris GL: Prediction and management of hyperkalemia across the spectrum of chronic kidney disease. Semin Nephrol 2014; 34:333-339.

18 Lever AF, Beretta-Piccoli C, Brown JJ, Davies DL, Fraser R, Robertson JI: Sodium and potassium in essential hypertension. BMJ (Clin Res Ed) 198;283:463-468.
19 Krishna GG: Effect of potassium intake on blood pressure. J Am Soc Nephrol 1990;1:4352.

20 Binia A, Jaeger J, Hu Y, Singh A, Zimmermann D: Daily potassium intake and sodium to-potassium ratio in the reduction of blood pressure: a meta-analysis of randomized controlled trials. J Hypertens 2015;33:1509-1520.

21 Mente A, O’Donnell MJ, Rangarajan S, McQueen MJ, et al: Association of urinary sodium and potassium excretion with blood pressure. N Engl J Med 2014;371:601-611.

22 Terker AS, Zhang C, McCormick JA, Lazelle RA, Zhang C, Meermeier NP, Siler DA, Park HJ, Fu Y, Cohen DM, Weinstein AM, Wang WH, Yang CL, Ellison DH: Potassium modulates electrolyte balance and blood pressure through effects on distal cell voltage and chloride. Cell Metab 2015;21:39-50.

-23 Rengarajan S1, Lee DH, Oh YT, Delpire E, Youn $\mathrm{JH}, \mathrm{McD}$ onough AA: Increasing plasma $\left[\mathrm{K}^{+}\right]$by intravenous potassium infusion reduces NCC phosphorylation and drives kaliuresis and natriuresis. Am J Physiol Renal Physiol 2014;306:F1059-F1068.

24 Terker AS, Zhang C, McCormick JA, Lazelle RA, Zhang C, Meermeier NP, Siler DA, Park HJ, Fu Y, Cohen DM, Weinstein AM, Wang WH, Yang CL, Ellison DH: Potassium modulates electrolyte balance and blood pressure through effects on distal cell voltage and chloride. Cell Metab 2015;21:39-50.

25 Krishna GG, Miller E, Kapoor S: Increased blood pressure during potassium depletion in normotensive men. N Engl J Med 1989;320: 1177-1182. 